than obtrusive foregrounds to the discussions. Each session of the conferences consisted of a general introduction to the topic, the statement of a case for discussion, contributions from two participants, and a summary of the results of discussion at the session. The topics dealt with were: the right to health care; life and death decisions in the neo-natal intensive care unit; animal rights and animal experimentation; informed consent in medical treatment; the refusal to sterilise; cost effectiveness and patient welfare; rational suicide, and government funding for elective abortions. The papers are all clear, readable and helpful at a practical level, and the introductions and summaries provide useful signposting to any reader lacking the time or patience to pick his or her way through the intricacies of philosophical argument. The moral outlooks of the participants vary as well as their disciplinary backgrounds. However, there is always an attempt to be fair to opposing views. For example, Professor Stanley Hauerwas, writing on suicide from the point of view of a professor of theology at the University of Notre Dame, avoids the slogans that might be expected from that position and offers a humane and balanced analysis.

The contributions vary in standard, as is obviously to be expected, but they are consistently controversial, and suitable for use with medical or nursing students. It is indeed a feature of the conferences that there is a large student involvement in the discussion. The editor himself, Marc D Basson, is described as 'currently a fourth-year medical student at the University of Michigan', and was the Director of the Committee on Ethics, Humanism, and Medicine at the time when this volume was produced. Another medical student participant, Rachel Lipson, was the committee's Programme Director. These are obviously exceptional students even by American standards, but there is no doubt that in Britain medical educators have been slow to see the need for systematic discussion and teaching in ethics. The view still prevails that if a doctor knows enough facts ethical problems will go away and that it is the business of medical education to provide these facts. This volume brings out clearly that ethical problems remain despite the facts, and that American medical education at least, is aware of this.

PROFESSOR R S DOWNIE Department of Moral Philosophy Glasgow University

\section{Medical Ethics and Medical Education}

\section{Eds Z Bankowski and J Corvera}

Bernardelli

Geneva, The Council for International

Organisations of Medical Science

$£ 6.00$ from Her Majesty’s Stationery

Office

The Council for International Organisations of Medical Science (CIOMS) is an international non-governmental scientific organisation established jointly by the United Nations Educational, Scientific and Cultural Organisation (Unesco) and the World Health Organisation (WHO) in I949. CIOMS holds annually a round table conference (usually on subjects related to ethics) and the proceedings are published. The present volume is a record of the $14^{\text {th }}$ conference which was held in Mexico City in 1980 and at which there were nearly 80 participants, mostly doctors but some philosophers, administrators and others. The conference consisted of four sessions: the first two constituted an ethical review of clinical research; the third was entitled Medical Ethics in Medical Education and the fourth Medical Education and Government. The title of the book (and indeed of the conference) is therefore misleading. Readers seeking observations on the relationship between ethics and medical education will be disappointed to find only one session on that subject. On the other hand, readers interested in the ethics of human experimentation will find much of interest but might miss the articles if they rely on the title.

The book consists of 20 papers, mostly in English with summaries in Spanish but a few in Spanish with English summaries. The 38 pages of discussion clearly cannot do justice to the participation, formal and informal, of all those attending. That being so, and the papers being on such diverse subjects there would be an argument for each of the opening papers to be published separately in an appropriate journal rather than for a volume of proceedings to be prepared. To say this is not to detract from the value and interest of the papers which are very readable: most of them offer new slants and some, new material, on subjects of perennial interest.

The tone of the sessions on ethical issues in human experimentation is set by a provocative paper by Dr J Ladd, Professor of Philosophy at Brown University, Providence, USA. His theme is that 'ethical aspects of human experimentation are dependent on the con- text' and that there is 'no special set of ethical principles that apply specifically and uniquely to human experimentation as distinct from other human activities'. He goes on to discuss certain confusions such as the moral and the legal aspects of informed consent and he lays stress on the relationship between experimental subjects and those who stand to benefit. There follows an interesting account by Dr R Levine of Yale of the value and limitations of ethical review committees. Further papers take specific examples to illustrate the problems of experimentation: gastroenterology, and here the emphasis is on the new invasive diagnostic procedures; children, and here there is a quotation from as recently as 1900 when the researcher found that animals were too expensive and so used orphanage children instead!, and women. These sessions on human experimentation are drawn together by a paper from Dr John Dunne of WHO who presents new provisional guidelines especially appropriate to developing countries. These were welcomed by the conference.

In the session on medical ethics in medical education Dr Edmund Pellegrino highlights the recent prominence given in medical education in the USA to humanities teaching. He discusses the best time for the teaching of ethics and the role of different teachers. He emphasises that 'teaching programmes rarely survive unless a substantial intellectual base is constantly added through research'. Dr Mark Siegler of the University of Chicago much prefers the term 'clinical ethics' to 'biomedical ethics' and emphasises the importance of focusing on issues that confront the doctor in day-to-day practice. He arranges a month's programme in clinical ethics to run concurrently with internal medicine and at 90-minute sessions three times a week a student presents for discussion the ethical aspects of a current case.

The session on medical education and government is interesting but the papers are virtually unrelated to ethics. A good attempt is made in the final discussion session to tie the whole conference together.

The book is to be recommended for its constituent parts rather than as a cohesive volume. Alfred Gellhorn, the chairman of these round table conferences, is to be congratulated on the topics chosen and on the high standard of the speakers invited.

A S DUNCAN

Emeritus Professor of Medical Education University of Edinburgh 